\title{
Erratum: Global world, global mind: Narratives of the University of Hong Kong Worldwide Exchange students
}

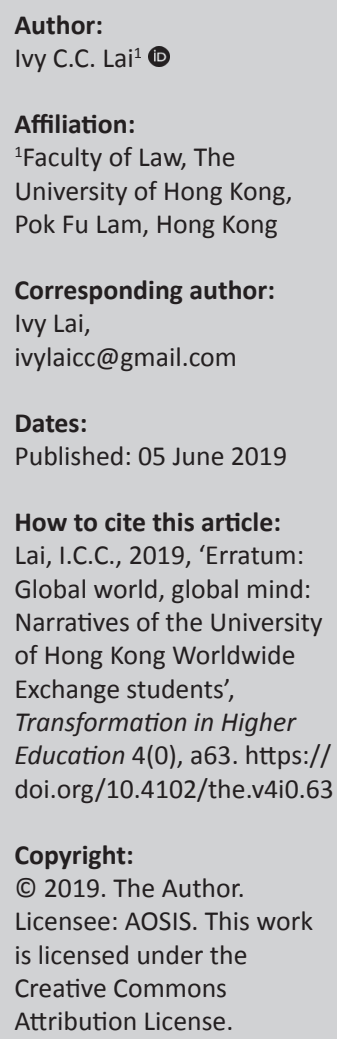

\section{Copyright:}

(C) 2019. The Author.

Licensee: AOSIS. This work

is licensed under the

Creative Commons

Attribution License.

In the 'how to cite' section of this article published in volume 3, Ivy C.C. Lai's initials were unintentionally misprinted as 'L.L. Lai'. The author's correct name is 'I.C.C. Lai'.

We hereby update and correct the 'how to cite' section as follows: Lai, I.C.C., 2018, 'Global world, global mind: Narratives of the University of Hong Kong Worldwide Exchange students', Transformation in Higher Education 3(0), a42. https:/ / doi.org/10.4102/the.v3i0.42

The publisher sincerely regrets this error and apologises for any inconvenience caused. 